\title{
Raman micro-spectrometry and its applications to the identification of inclusions in natural rubies
}

\author{
Nguyen Quy Dao and L. Delaigue \\ Laboratoire SPMS, École Centrale de Paris, Grande voie des Vignes, 92295 Châtenay-Malabry Cedex, France
}

Confocal micro-Raman spectrometry is particularly suitable for analysing the chemical nature of inclusions in gems, thus providing useful information on their origin, their authenticity, their conditions of formation, or unnatural treatments. This article gives some results obtained for Vietnamese rubies which have been discovered in the recent years.

\section{Introduction}

Raman spectrometry is an analytical method based on the interaction of light and molecular and/or lattice motions (vibration, rotation and translation motions). This technique presents several advantages : it is non-destructive, quick, precise, very easy to use and requires no sampling. Distinctive Raman imaging is now also available.
Concerning the study of minerals and gems, considerable progress was made once the coupling of a Raman spectrometer with an optical microscope became possible. Historically, this system was developed at the same time by French and American researchers [1-5]. A dedicated microscope, through which the exciting laser beam and the backscattered signal both pass is used to examine a sample and to send the Raman signals to the spectrometer. Such a device allows the exciting beam to be focussed on a small volume of the sample and the Raman spectrum of this volume to be collected. It is thus possible to study microcrystals (Fig. 1). Technical improvements have been added to the basic technique to increase its performances. The confocal mount is an important one which consists in placing a hole in the image focal plane of the microscope, in order to suppress from the signal all beams not from the focal plane. The confocal mount allows a good vertical resolution to be achieved whereas this would be impossible with a standard mount [6]. It is consequently possible to measure two- or three-dimensional maps of samples, which is very interesting for the study of inhomogeneous samples, of di- or triphasic inclusions, and for numerous other applications [7-8]. 
The identification of inclusions in natural stones provides interesting information on their genesis such as their conditions of formation, secondary reactions, or unnatural treatments. In our Laboratory, Raman micro-spectrometry has been used for analysing natural ruby samples. Our goal was to investigate the possibility of distinguishing several ruby deposits by examining the chemical nature and the frequency of inclusions in a given natural gem.

\section{Experimental procedures}

The first step in such a study consists in building a Raman database of various minerals that might be found as inclusions in natural rubies or other stones. We built our own database [9], since such spectra were rare, incomplete or not available. A database already existed, but it was not complete enough for our needs [10]. At present, it is possible to find interesting updated regularly data at the following Internet address:

http://minerals.gps.caltech.edu/files/raman/Caltech_data/index.htm

The analysis of inclusions can be carried out easily, quickly, and with a very simple sampling operation. Thick blades are the best samples, but it is also possible to analyse cut gemstones. Rough surfaces are not recommended as it is difficult to examine the inside of the sample and to focus the laser beam accurately on the inclusion. For our study, we used $1 \mathrm{~mm}$ thick polished ruby samples. They were studied with a LABRAM I (DILOR, ISA) using a SpectraPhysics Ar+ laser as the source. A $\times 50$ microscope objective with a long working distance $(8 \mathrm{~mm})$ allowed the examina-

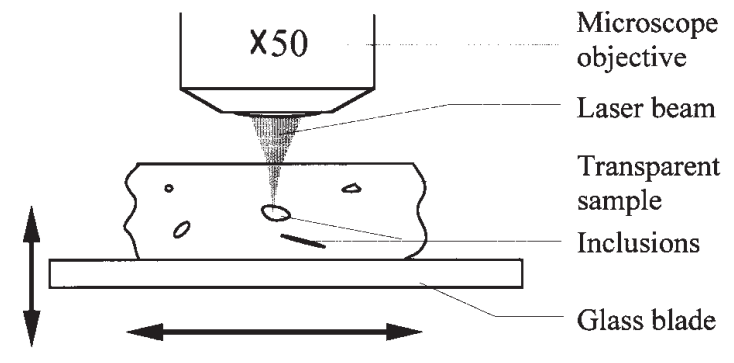

Figure 1. Principle scheme of Raman micro-spectrometry applied to the analysis of inclusions.

tion of inclusions deep inside the host crystal. Inclusions ranging from some microns to hundreds of microns in size were studied.

There are several problems that can arise: when studying inclusions, the host matrix can partly absorb the laser beam, depending on its wavelength, consequently making the measurement of deep inclusions difficult. For rubies where the $514.5 \mathrm{~nm}$ wavelength of an $\mathrm{Ar}+$ laser is used, inclusions located beyond $800 \mathrm{~mm}$ in depth are difficult to study. Turning the sample upside down solved the problem in our case. Another difficulty which can frequently be encountered is fluorescence. In the case of ruby, there is very strong fluorescence due to the well-known R-lines situated in the red region and used in the ruby laser (Fig. 2). Consequently, when the $632.8 \mathrm{~nm}$ line of a He-Ne laser is used as

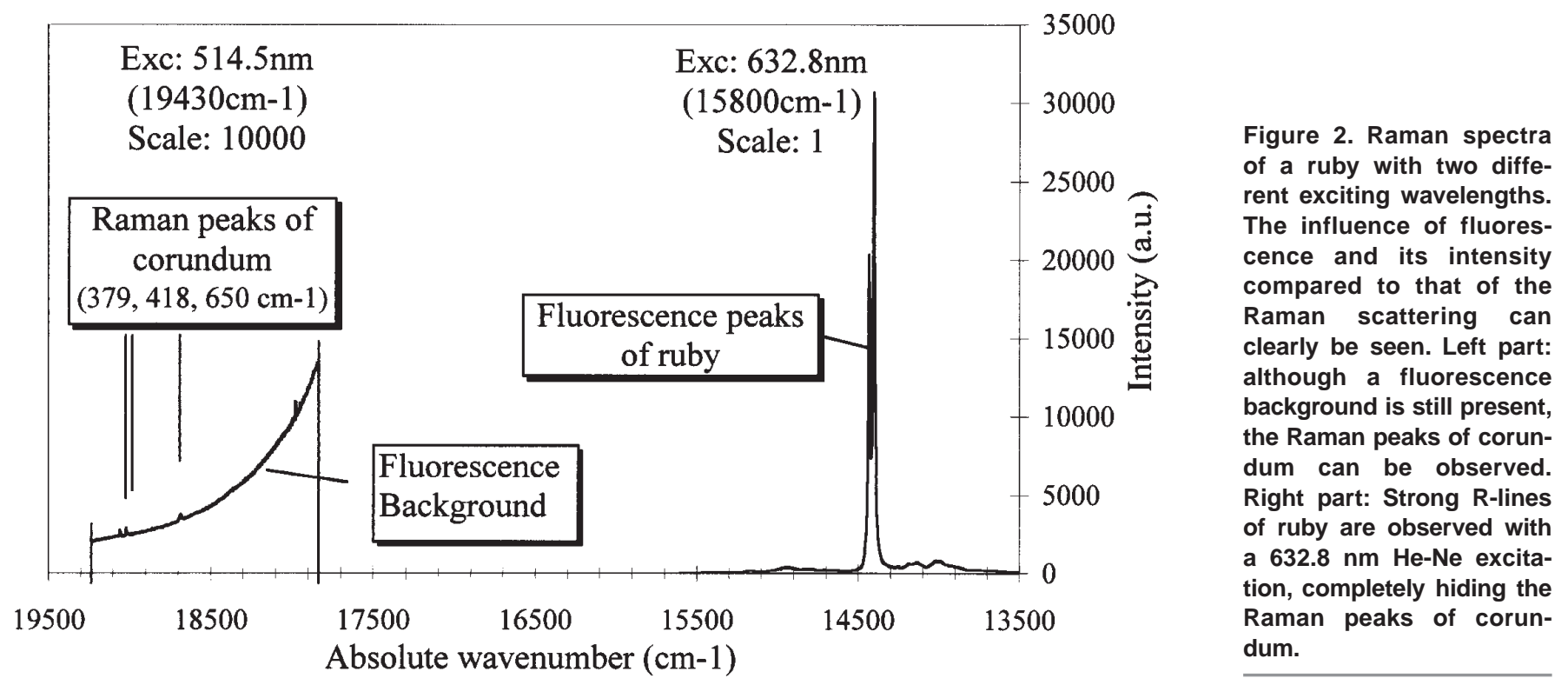


excitation radiation only a very strong fluorescence emission is observed, completely hiding the very weak Raman lines of corundum. With a $514.5 \mathrm{~nm}$ excitation of an Ar+ laser, a strong background is still observed on the Raman spectrum, and increases for high wavenumbers (they are closer to the R-lines). A solution can be to work with a $488.0 \mathrm{~nm}$ wavelength, in order to be even further away from the R-lines. The spectra are less noisy, and the measurement is more sensitive. The $488.0 \mathrm{~nm}$ wavelength presents another advantage as it is located almost at the minimum absorption of ruby. Consequently, the fluorescence excited by this wavelength is weaker than that excited with $514.5 \mathrm{~nm}$ wavelength. However, in all cases, it is impossible to measure the peak of $\mathrm{H}_{2} \mathrm{O}$, located around $3400 \mathrm{~cm}^{-1}$, too close to the R-lines. It must also be noted that the Raman peaks are about a hundred thousand times weaker than the ruby fluorescence. In the case of natural rubies, as the fluorescence background depends on impurities and/or trace elements, the variation of the background compared to the Raman peaks intensities can in some cases indicate the origin of the stone (Fig. 3). This is the reason why all our samples were examined with the $514.5 \mathrm{~nm}$ wavelength.

There are some other difficulties to overcome. The Raman spectrum of a single crystal is strongly dependent on its orientation due to the polarisation effect. This is true for the host matrix and the inclusions. As the last ones can be randomly placed in the host crystal, the recorded Raman spectra can drastically vary in shape and intensity for inclusions of the same nature but differently oriented. It is sometimes difficult to identify an inclusion just by comparison with the spectra of the database. It is necessary to turn the sample and study it in different positions in order to change the orientation of both the host matrix and the inclusion. A correct spectrum can be obtained by averaging these different spectra.

The last problem is that inclusions of different minerals can have the same or very close Raman spectra. For example, this is the case for the different forms of $\mathrm{CaCO}_{3}$ : calcite, aragonite and other carbonates have very similar spectra [11], making them difficult to distinguish.

\section{Results}

The present paper shows the results recently obtained when examining 164 and 100 ruby samples originating from the Luc Yen and Quy Chau mines respectively, both recently discovered and exploited in Vietnam. Figures 2-5 and photo 1 show some interesting features of inclusions found in these rubies. In addition, we have detected complex inclusions containing both gaseous and liquid $\mathrm{CO}_{2}$ (Fig. 4, photo. 2), and another very interesting type of inclusion, which seems to contain sulphured compounds. These last inclusions present a spectrum which evolves with time: the peaks of a certain type of sulphur (probably with $\mathrm{S}_{3}{ }^{2-}$ ions)

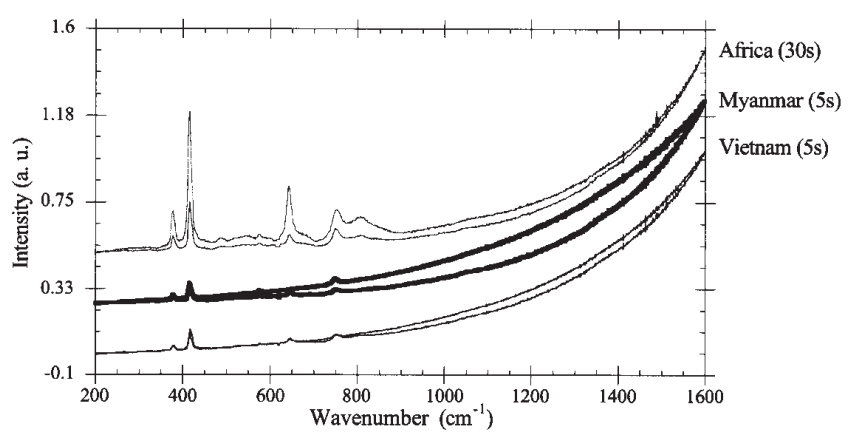

Figure 3. General shapes of the Raman spectra of African, Vietnamese and Burmese rubies.

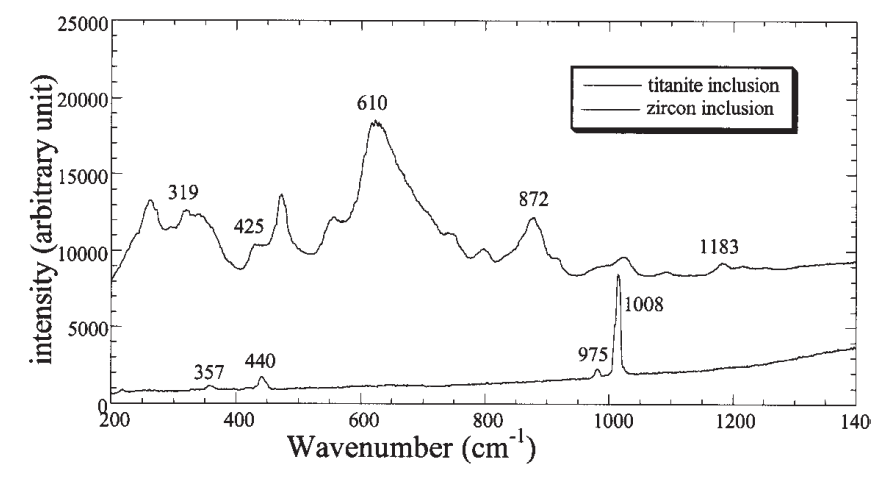

Figure 4. Raman spectra of titanite and of zircon inclusions in a Luc Yen ruby.

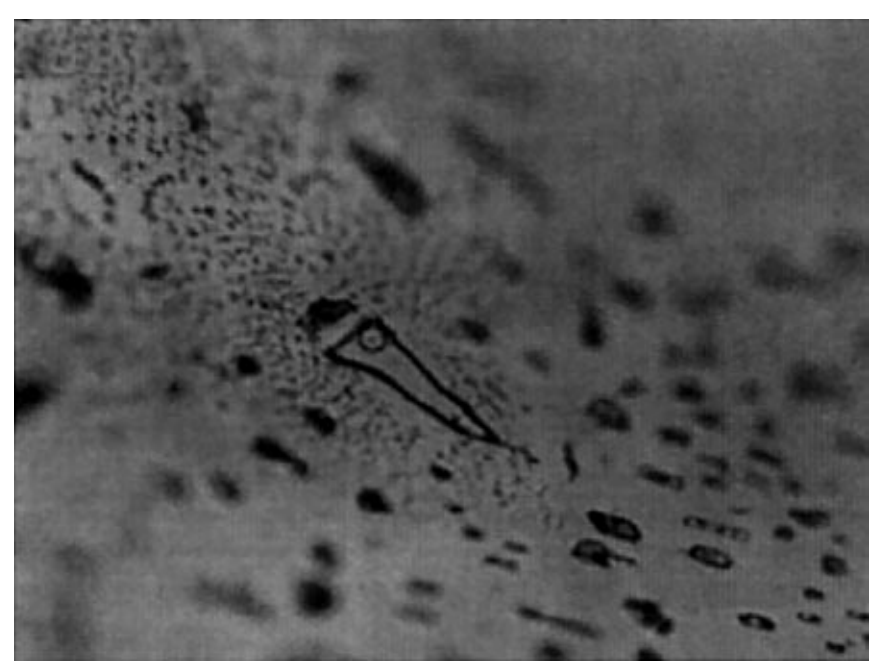

Photo 1. Bottle shaped diphasic inclusion: liquid and gaseous $\mathrm{CO}_{2}$. 


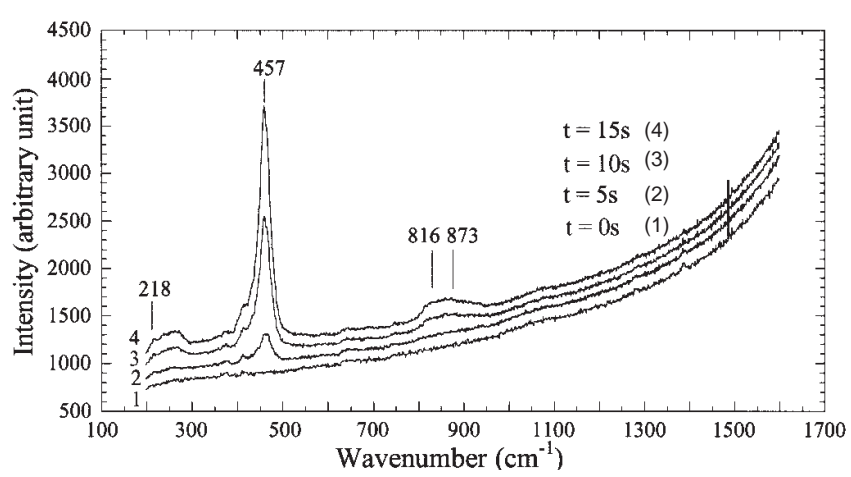

Figure 5. Raman spectra of an inclusion containing sulfured compounds interacting with the laser light. The sulfur peaks appear and grow with time. The spectra are measured every 2 seconds during 2 seconds.

appear and increase with time (Fig. 5), due to a photochemical reaction that has not yet been clearly identified.

Table I indicates in the first column the inclusions definitely identified in rubies of the two Vietnamese mines. If the number of times these inclusions occur in a sample is counted, it is possible, using statistical methods, to estimate the probability of a ruby coming from one or the other mine. By fixing the limit of the Khi-square test value (last column of Table I) at more than $5 \%$, which is considered as

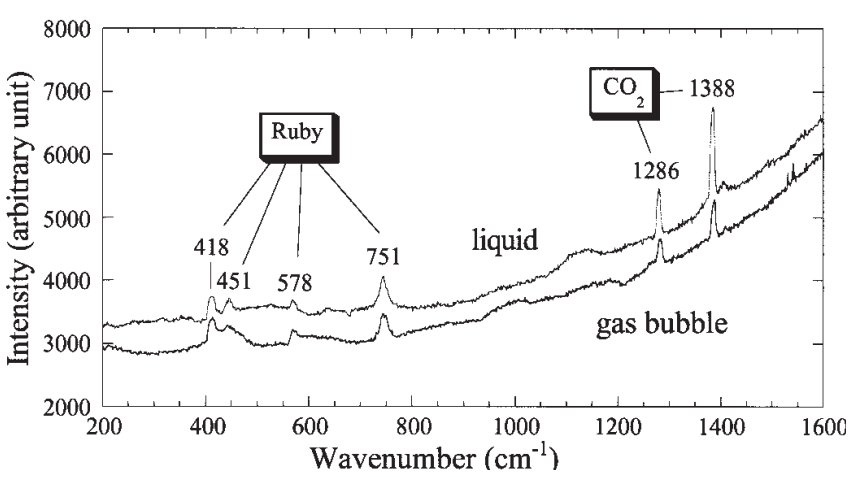

Figure 6. Raman spectra of an $\mathrm{CO}_{2}$ diphasic inclusion. The presence of diaspore (D), of $\mathrm{CO}_{2}$ and of sulfur (S) can be seen simultaneously in a same inclusion. The peaks of sulfur increase rapidly once they start to appear, as it has been observed in fig.5. (R) are peaks of the ruby host.

statistically significant, it can be seen that anatase, apatite, $\mathrm{CO}_{2}$, rutile, sulfur and zircon are characteristic of one of the two mines, i.e. their relative abundancies differ significantly between the two mines. Anatase, $\mathrm{CO}_{2}$, rutile, and sulfur inclusions are more frequent in Quy Chau rubies while apatite and zircon are more frequent in Luc Yen rubies. Conversely, Table I shows that with a $57.7 \%$ probability of Khi-square value for diaspore in these two mines, diaspore does not allow the distinction of the stones coming from these two mines but confirms on the other hand the

Table I.

\begin{tabular}{|c|c|c|c|c|c|c|}
\hline & $\begin{array}{l}\text { Number of } \\
\text { inclusions }\end{array}$ & $\begin{array}{l}\text { Luc Yen } \\
\text { Number of } \\
\text { samples }\end{array}$ & $\begin{array}{c}\% \text { of } \\
\text { samples }\end{array}$ & $\begin{array}{l}\text { Number of } \\
\text { inclusions }\end{array}$ & $\begin{array}{c}\text { Quy Chau } \\
\text { Number of } \\
\text { samples }\end{array}$ & $\begin{array}{c}\% \text { of } \\
\text { samples }\end{array}$ \\
\hline Anatase & 2 & 2 & 1.2 & 11 & 10 & 10.0 \\
\hline Apatite & 30 & 14 & 8.5 & 2 & 2 & 2.0 \\
\hline Calcite & 712 & 68 & 41.4 & 179 & 46 & 46.0 \\
\hline Graphite & 18 & 15 & 9.1 & 10 & 7 & 7.0 \\
\hline $\mathrm{CO}_{2}$ & 94 & 36 & 21.9 & 211 & 37 & 37.0 \\
\hline Diaspore & 210 & 63 & 38.4 & 144 & 35 & 35.0 \\
\hline Limonite & 8 & 4 & 2.4 & 2 & 2 & 2.0 \\
\hline Muscovite & 139 & 11 & 6.7 & 32 & 4 & 4 \\
\hline Monazite & 5 & 2 & 1.2 & - & - & - \\
\hline Nepheline & 29 & 11 & 6.7 & 5 & 2 & 2.0 \\
\hline Pyrite & 50 & 6 & 3.6 & - & - & - \\
\hline Rutile & 107 & 27 & 16.4 & 118 & 28 & 28.0 \\
\hline Sulphur & 105 & 22 & 13.4 & 109 & 32 & 32.0 \\
\hline Titanite & 100 & 25 & 15.2 & 41 & 11 & 11.0 \\
\hline Zircon & 135 & 38 & 23.1 & 24 & 11 & 11.0 \\
\hline
\end{tabular}




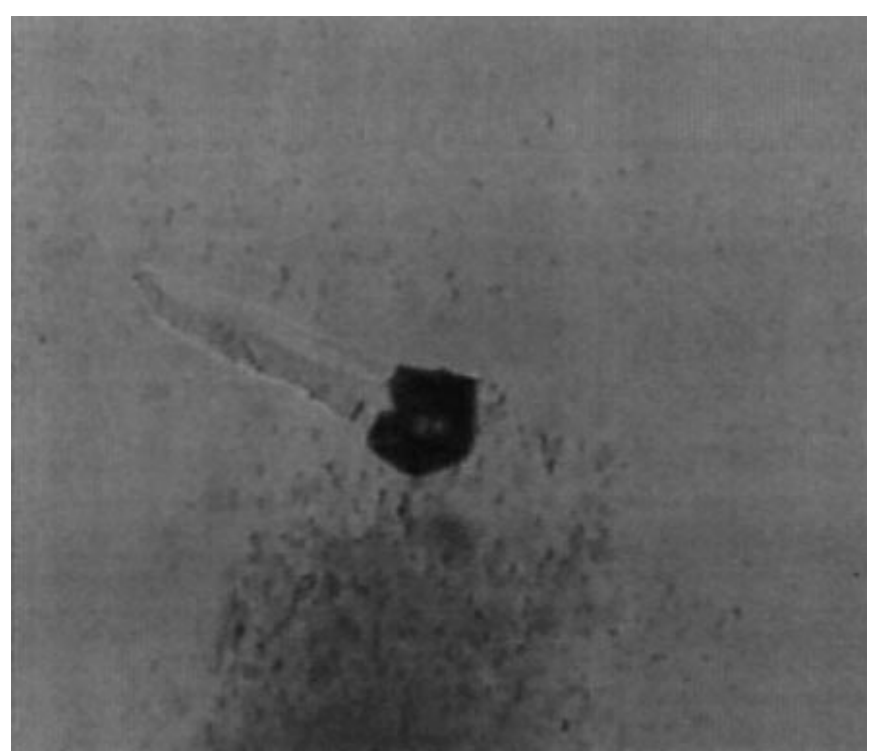

Photo 2. Bottle shaped diaspore inclusion: diaspore is located in the dark part. This shape is the same as for $\mathrm{CO}_{2}$ inclusion and it is quite often to find $\mathrm{CO}_{2}$ in this kind of diaspore inclusion.

geological hypothesis [12] that Vietnamese rubies could be formed from diaspore or boehmite, following the chemical reaction:

$$
2 \mathrm{AlO}(\mathrm{OH}) \rightarrow \mathrm{Al}_{2} \mathrm{O}_{3}+\mathrm{H}_{2} \mathrm{O}
$$

\section{Conclusion}

Despite some limitations inherent to the method, Raman micro-spectrometry is very powerful. We have been able to identify hundreds of inclusions of about 20 different natures, which has allowed us to establish a statistical difference between the two Vietnamese ruby mines. It is however illusive to try identifying one gemstone by just examining the presence (or absence) of inclusions by Raman micro-spectrometry especially when one knows that valuable gemstones are generally free or contain very few inclusions. When the number of samples is high, it is then possible by examining the presence of inclusions to identify the origin of these stones and the chemical nature of the inclusions allow their geological characteristics to be better understood.

\section{References}

1. Delhaye M.; Dhamelincourt P., Proc. $4^{\text {th }}$ Inter Conf Raman Spectrosc. Brunswick, 1974.

2. Delhaye M.; Dhamelincourt P., J. Raman Spec. 1975, 3, 3343.

3. Rosasco G.J.; Etz E.S.; Cassat W.A., Proc. $4^{\text {th }}$ Inter. Conf. Raman Spectrosc. Brunswick, 1974.

4. Rosasco G.J.; Etz E.S.; Cassat W.A., Appl. Spectrosc. 1975, 19, 396-404.

5. Rosasco G.J.; Roedder E.; Simmons J.H., Science 1975, 190, 557-560.

6. Tabaksblat R.; Meier R.J.; Kip B.J., Appl. Spectrosc. 1992, 46, 60-68.

7. Govil A.; Pallister D.M.; Morris M.D., Appl. Spectrosc. 1993, 47, 75-79.

8. Brenan C.J.H.; Hunter I.W., Appl Spectrosc. 1995, 49, 971976.

9. Delaigue L.; Nguyen Quy Dao, to be published.

10. Schubnel H.J.; Pinet M.; Smith D.C.; Lasnier B. Rev. Gemmol. A.F.G. 1992, hors série.

11. Nguyen Quy Dao; Daudon M., Infrared and Raman Spectra of Calculi, Paris: Elsevier Ed., 1997.

12. Kammerling R.C.; Scarrat K.; Bosshart G.; Jobbins E.A.; Kane R.E.; Gübelin E.J.; Levinson A.A. J. Gemmology 1994, 24, 340. 